\title{
Erratum to: Chemical Characteristics and Utilization of Coal Mine Drainage in China
}

\author{
Qiyan Feng $\cdot$ Ting Li $\cdot$ Bin Qian
}

Lai Zhou • Bo Gao $\cdot$ Tao Yuan

Published online: 25 June 2014

(c) Springer-Verlag Berlin Heidelberg 2014

\section{Erratum to: Mine Water Environ}

\section{DOI 10.1007/s10230-014-0271-y}

The authors would like to correct errors in the original publication as detailed below.

1. In the third paragraph of Introduction "97\% of China's coal is produced by underground mining" should read as "90\% of China's coal is produced by underground mining".

2. The correct version of the Fig. 1 is given below.

The online version of the original article can be found under doi:10.1007/s10230-014-0271-y.

Q. Feng $(\bowtie) \cdot$ T. Li · B. Qian · L. Zhou · B. Gao · T. Yuan School of Environment Science and Spatial Informatics, China University of Mining and Technology,

Xuzhou 221116, China

e-mail: fqycumt@126.com

T. Li · L. Zhou

State Key Laboratory of Coal Resources Safe Mining, China University of Mining and Technology,

Xuzhou 221116, China 
Fig. 1 The distribution of water samples for 269 coal mines in China

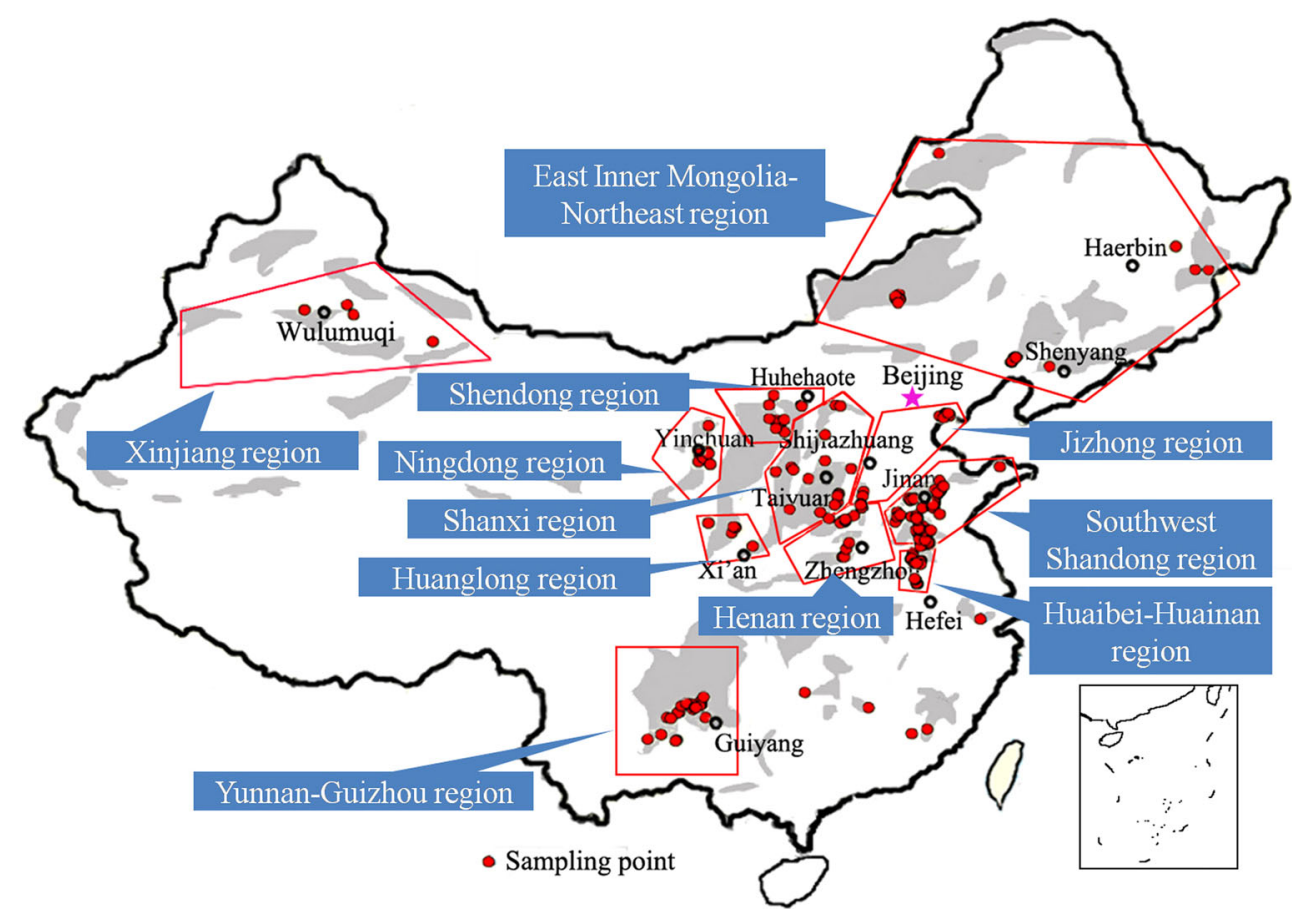

